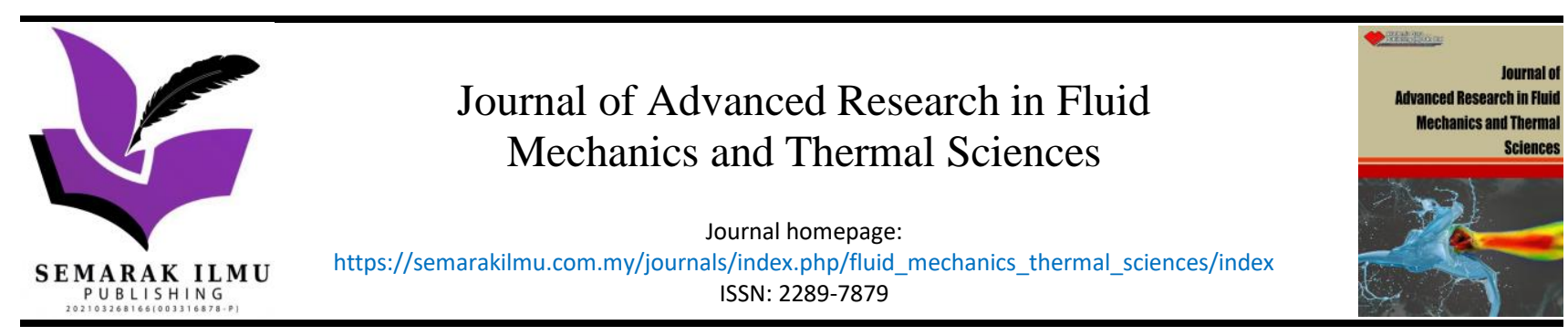

\title{
Rheological Properties of $\mathrm{TiO}_{2} / \mathrm{POE}$ Nanolubricant for Automotive Air- Conditioning System
}

\author{
Abdul Hamid Hamisa ${ }^{1,3}$, Wan Hamzah Azmi ${ }^{1,2, *}$, Taib Mohd Yusof ${ }^{1}$, Mohd Farid Ismail ${ }^{1,4}$, Anwar \\ Ilmar Ramadhan ${ }^{1,5}$ \\ 1 Department of Mechanical Engineering, College of Engineering, Universiti Malaysia Pahang, Lebuhraya Tun Razak, Gambang, Kuantan 26300 \\ Pahang, Malaysia \\ 2 Centre for Research in Advanced Fluid and Processes, Universiti Malaysia Pahang, Lebuhraya Tun Razak, Gambang, 26300 Kuantan, Pahang, \\ Malaysia \\ 3 School of Engineering, Faculty of Science, Engineering and Agrotechnology, University College of Yayasan Pahang, Taman Gelora, Jln Dato' \\ Abdullah, Kuantan 25050 Pahang, Malaysia \\ 4 Faculty of Mechanical and Manufacturing Engineering Technology, Universiti Teknikal Malaysia Melaka, Hang Tuah Jaya 75150, Durian Tunggal, \\ Melaka, Malaysia \\ 5 Faculty of Engineering, Universitas Muhammadiyah Jakarta, Jl. Cempaka Putih Tengah 27, Jakarta 10510, Indonesia
}

ARTICLE INFO ABSTRACT

\section{Article history:}

Received 14 August 2021

Received in revised form 5 November 2021

Accepted 10 November 2021

Available online 7 December 2021

\section{Keywords:}

compressor lubricant; dynamic viscosity; nanolubricant; refrigeration; rheology properties

\begin{abstract}
The enhancement of nanolubricant rheological properties can improve the performance of automotive air-conditioning systems. The rheological properties of the $\mathrm{TiO}_{2} / \mathrm{POE}$ nanolubricant were investigated in this study at 0.01 to $0.1 \%$ volume concentrations and temperatures ranging from 0 to $100^{\circ} \mathrm{C}$. $\mathrm{TiO}_{2}$ nanoparticles were dispersed in the base lubricant of Polyol-ester (POE RL68H) lubricant in two steps. The dynamic viscosity was measured with an Anton-Paar Rotational Rheometer. According to the findings, the $\mathrm{TiO}_{2} / \mathrm{POE}$ nanolubricant behaved as Newtonian fluids at all volume concentrations and temperatures. The dynamic viscosity increment of nanolubricants up to $1.75 \%$ only occurred for $0.1 \%$ volume concentration and temperature of 90 to $100^{\circ} \mathrm{C}$. Meanwhile, when compared to POE lubricant, nanolubricants with volume concentrations of 0.01 and $0.05 \%$ showed a decrement trend in dynamic viscosity of up to $1.8 \%$. Finally, the $\mathrm{TiO}_{2} / \mathrm{POE}$ nanolubricant improved the rheological properties of the POE lubricant for use in automotive air-conditioning systems.
\end{abstract}

\section{Introduction}

Lubrication is the best method of reducing friction and applying for mechanical movement systems. Lubrication technology is always in high demand. As a result, various methods have been developed to improve the capability of lubricant for various applications. One of method is the use of nanoparticles in lubricants. Nanolubricant can improve the energy conservation.

According to the literature, almost $30 \%$ of energy is lost because of friction and wear [1]. Nanolubricants are colloidal suspensions in which nanosized particles are dispersed in the base oils.

\footnotetext{
* Corresponding author.

E-mail address: wanazmi2010@gmail.com
}

https://doi.org/10.37934/arfmts.90.1.1022 
Basically, there are three major components in preparation of nanolubricants. The first component is base oils. The base oils are classified into three types of oils namely mineral oils, synthetic oils and vegetable oils. The second component is additives. The additives can be classified into two types namely nano additives and chemical additives. Nano additives are nanoparticles, whereas chemical additives are antioxidants, AW, EP, PPD corrosion inhibitors, and others. Nanoparticle dispersion as nano additives has been widely used in a variety of industries including biomedical, health care, food agriculture, industrial, electronics, environment, renewable energy, and textile [2-6].

Before proceeding to the next step of property evaluation, the stability of the nanolubricant must be considered. Previous researchers conducted a stability investigation as well [7-10]. The thermophysical properties or rheological properties of nanolubricants are then investigated for the best stability condition. Many researchers studied thermo-physical properties such as thermal conductivity, rheology, viscosity, and density [11-16]. The performance of air-conditioning system is one of major concern in automotive system as reviewed by Zhang et al., [17] and Datta et al., [18]. One of the most effective methods for improving the performance of an automotive air-conditioning (AAC) system is to disperse nanoparticles in base lubricants. The nanolubricants can be used in the automotive industry to improve the performance of the air-conditioning system. The first nanolubricant generation concentrated on monotype nanoparticles dispersed in the base lubricant. Sharif et al., [19] investigated the effect of adding Al2O3 nanoparticles to PAG lubricants. While Krishnan et al., [20] examined the use of nanoparticles in a vapour compression refrigeration system.

The fuel consumption is important and significant factor in the operation of AAC system [21]. The fuel consumption of vehicles was increased up to $27 \%$ with the use of the AAC system [22]. However, for the case of hybrid electrical vehicles (HEV) or commonly known as hybrid cars, it is not only affecting the fuel consumption but also the energy consumption from the battery itself. A study on the performance of an electric compressor in a non-electric vehicle was carried out by Dahlan et al., [23]. They discovered that a direct current (DC) compressor can be used in a conventional nonelectric vehicle with lower fuel consumption. As a result, the use of an electric driven compressor (EDC) outperforms a conventional car. When compared to a belt-driven compressor, the EDC improves performance by 15 to $54 \%$. In addition, this also can cause the fuel reduction percentage between 5 to 14\% [24]. The energy saving for AC compressor with nanolubricant was investigated by Sharif et al., [25]. The SiO2/PAG nanolubricant was reduced the compressor work for up to $16.5 \%$.

The improvement in performance and energy saving of AAC systems are related to the characteristics or properties of nanolubricants. The viscosity effect and rheological properties are vital to be investigated. The majority of research findings demonstrated the increment of viscosity with increasing the volume concentration, while decrement of viscosity with increasing temperature. Table 1 presented previous research on the rheological properties of nanolubricants.

As a result, finding and innovating AAC solutions for HEVs or EVs is critical [29]. The demand for new technology in HEVs has prompted many researchers to improve the performance and energysaving capabilities of the AAC system. $\mathrm{TiO}_{2} / \mathrm{POE}$ nanolubricant will be used in the air-conditioning system of a hybrid electric vehicle (HEV) in this paper. For AAC, common vehicles use a belt-driven compressor, whereas HEVs use an electric-driven compressor (EDC). Because HEVs require a different type of compressor, they require a different base lubricant. PAG lubricant is primarily used in common AAC systems, whereas POE lubricant is primarily used in HEV systems. As a result, the goal of this research is to determine the stability and rheological properties of the $\mathrm{TiO}_{2} / \mathrm{POE}$ nanolubricant for use in the HEV AAC system. 


\section{Table 1}

Summarizes previous research on the rheological properties of nanolubricants

Nanolubricants
$\mathrm{TiO}_{2}$ nanoparticles in raw mineral oils as a
lubricant additive [26]
Summary of finding lubricant additive [26] its viscosity. The friction coefficient decreases as the volume fraction of the nanoparticle additive increases. The authors proposed $0.01 \%$ as the optimal volume $\mathrm{Al}_{2} \mathrm{O}_{3} /$ PAG nanolubricant [19] concentration for optimal performance.

The results showed that increasing the volume concentration increased viscosity while increasing the temperature decreased viscosity. The authors suggested using $\mathrm{Al}_{2} \mathrm{O}_{3} /$ PAG nanolubricants with a volume concentration of less than $0.3 \%$ for use in automobile air conditioning systems.

Nanoparticles of $\mathrm{SiO}_{2}$ and $\mathrm{Al}_{2} \mathrm{O}_{3}$ dispersed in $\mathrm{PAG} \mathrm{SiO}_{2}$ nanolubricants have a viscosity that increases lubricant [27] with volume concentration but decreases with temperature. The authors advocated for the use of $\mathrm{SiO}_{2}$ nanolubricants with a volume concentration of less than $1.0 \%$ in automobile air conditioning systems.

$\mathrm{Al}_{2} \mathrm{O}_{3} / \mathrm{POE}$ and $\mathrm{ZnO} / \mathrm{POE}$ nanolubricants [28] With increasing nanoparticle mass fraction, the liquid viscosity, density, and thermal conductivity increased. As the temperature rose, the viscosity and density decreased.

\section{Methodology}

\subsection{The Properties of Material}

$\mathrm{TiO}_{2}$ nanoparticles and the lubricant-based type Polyol-Ester (POE) RL68H were used in the preparation of nanolubricants. HWNANO was used to obtain the $\mathrm{TiO}_{2}$ nanoparticles (Hongwu International Group Ltd). The size is $50 \mathrm{~nm}$, and the purity is $99.9 \%$. POE lubricants are widely used in refrigerators, commercial air-conditioning systems, hybrid cars, and other vehicles with electrically powered compressors (EDC). The $\mathrm{TiO}_{2}$ nanoparticles were dispersed in the POE RL68H base lubricant. Table 2 lists the nanoparticle's specific properties. Table 3 shows the properties of the Polyol-Ester (POE) RL68H. Transmission Electron Microscopy (TEM) was used to characterize the $\mathrm{TiO}_{2} / \mathrm{POE}$ nanolubricant. Figure 1 shows a TEM image of a nanolubricant. By examining the particle distribution in the TEM image, it was clear that the size of $\mathrm{TiO}_{2}$ nanoparticles is uniform and irregular in shape. While suspended in POE lubricants, the nanoparticles demonstrated good dispersion and less agglomeration.

Table 2

Properties of $\mathrm{TiO}_{2}$ nanoparticle $[8,30]$

\begin{tabular}{lll}
\hline Properties & Unit & $\mathrm{TiO}_{2}$ \\
\hline Thermal Conductivity & $\mathrm{W} \mathrm{m}^{-1} \mathrm{~K}^{-1}$ & 8.4 \\
Specific heat & $\mathrm{J} \mathrm{kg}^{-1} \mathrm{~K}^{-1}$ & 692 \\
Density (at 293 K) & $\mathrm{kg} \cdot \mathrm{m}^{-3}$ & 4230 \\
Mass of molecular & $\mathrm{g} \mathrm{mol}$ & 79.86 \\
Average particle diameter & $\mathrm{nm}$ & 50 \\
\hline
\end{tabular}




\section{Table 3}

POE RL68H lubricant properties [31]

\begin{tabular}{lll}
\hline Properties & Unit & POE RL68H \\
\hline Viscosity $\left(\right.$ at $\left.40^{\circ} \mathrm{C}\right)$ & $\mathrm{cSt}$ & 66.6 \\
Viscosity $\left(\right.$ at $\left.100^{\circ} \mathrm{C}\right)$ & $\mathrm{cSt}$ & 9.4 \\
Pour Point & ${ }^{\circ} \mathrm{C}$ & -39 \\
Density $\left(\right.$ at $\left.20^{\circ} \mathrm{C}\right)$ & $\mathrm{g} / \mathrm{ml}$ & 0.977 \\
Flash Point COC & ${ }^{\circ} \mathrm{C}$ & 270 \\
\hline
\end{tabular}

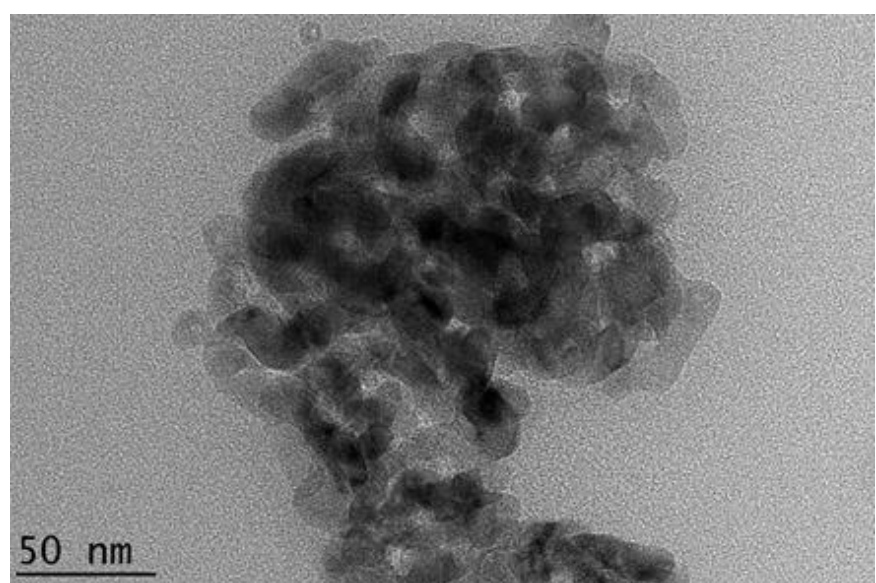

Fig. 1. TEM Image for $\mathrm{TiO}_{2} / \mathrm{POE}$ nanolubricant at $50 \mathrm{~nm}$

\section{$2.2 \mathrm{TiO}_{2} / \mathrm{POE}$ Nanolubricant Preparation}

In order to make the nanolubricant, a two-step technique was used [32]. It was also used in previous studies $[33,34]$. $\mathrm{TiO}_{2}$ nanoparticles and POE base lubricant were combined. The mass of $\mathrm{TiO}_{2}$ nanoparticles was measured to begin the preparation of the nanolubricant. The volume concentration of the nanolubricant was calculated using Eq. (1) [33, 35].

$\varnothing=\frac{m_{p} / \rho_{p}}{m_{p} / \rho_{p}+m_{L} / \rho_{L}} \times 100$

As shown in Figure 2, the nanoparticle was filtered with a strainer during the weighing process. Before being dispersed in the POE lubricant, the strainer was used in the nanolubricant preparation process to reduce the agglomeration size. The nanoparticles were then dispersed in POE lubricants and stirred for 30 minutes with a magnetic stirrer before being sonicated. To improve the stability of the nanolubricant, the sonication process used an ultrasonic bath with ultrasonic pulses of $100 \mathrm{~W}$ and $36(+/-3) \mathrm{kHz}$. The $\mathrm{TiO}_{2} / \mathrm{POE}$ nanolubricant in this study was prepared at volume concentrations of $0.01,0.03,0.05,0.07$, and $0.1 \%$. The nanolubricant was created by reducing the concentration from the highest to the lowest. 


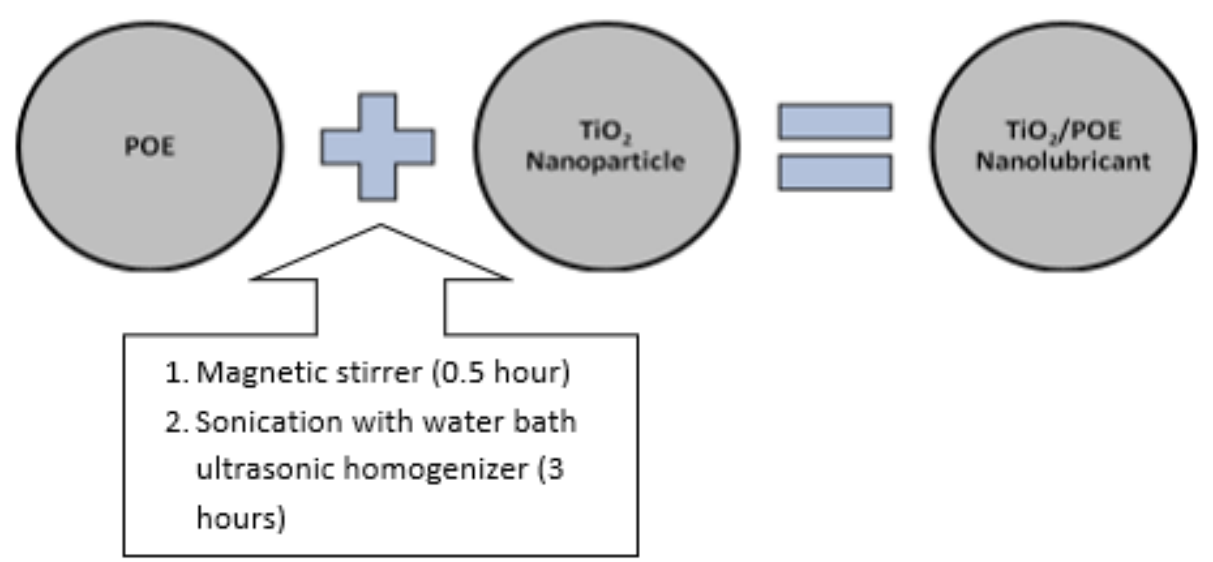

Fig. 2. Two step method process in preparing the nanolubricant

\subsection{The Nanolubricant Stability}

Quantitative and qualitative methods were used to test the stability of nanolubricant. Visual observation of sedimentation was utilized as a qualitative method. This study lasted a minimum of 14 days and a maximum of 60 days $[30,33,36]$. The nanolubricant is said to be stable when the concentration ratio remains constant over time [37]. Then, as illustrated in Figure 3 , the quantitative approach used an Ultraviolet-Visible (UV-Vis) spectrophotometer. By comparing the intensity level with the base lubricants, the UV-Vis was utilized to calculate the sample's peak absorption wavelength and absorbance value [38]. By adjusting the sonication period, the UV-Vis measurement was carried out for at least 14 days (340 hours). The UV-Vis spectrophotometer's peak wavelength was discovered to be $530 \mathrm{~nm}$. The peak absorption wavelength of the $\mathrm{TiO}_{2} / \mathrm{POE}$ nanolubricant was determined by scanning the absorbance of the $\mathrm{TiO}_{2} / \mathrm{POE}$ nanolubricant with a variety of wavelengths at a constant $0.01 \%$ volume concentration [36]. Previous research had also employed UV-Vis to assess stability such as Sharif et al., [25] and Yu \& Zie [32].

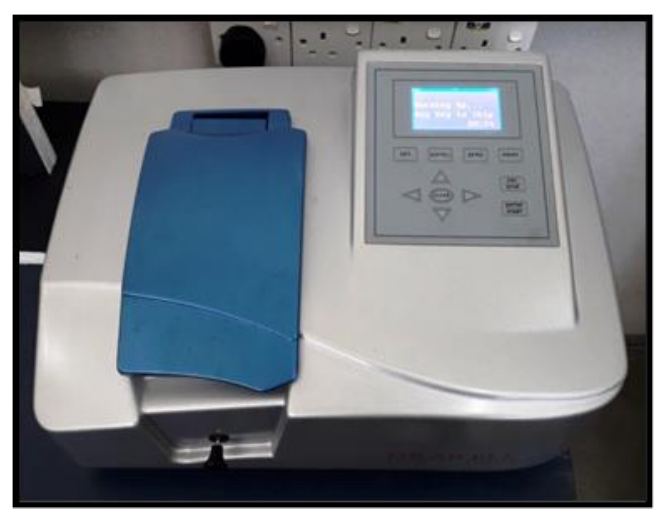

Fig. 3. UV-Vis Spectrophotometer

\subsection{Dynamic Viscosity Measurements}

The $\mathrm{TiO}_{2} / \mathrm{POE}$ nanolubricant's dynamic viscosity was measured using the Anton-Paar Rotational Rheolab QC, as shown in Figure 4, at varied temperatures between 30 and $100{ }^{\circ} \mathrm{C}$ and different volume concentrations. The data was collected in the range of 0 to $1.0 \mathrm{mPa}$.s and a torque range of 10 to $100 \%$. The torque notion was used in the rotational viscometer. To rotate the liquid, torque was necessary, which was a component of the liquid's viscosity. It will cause the liquid's viscous drag 
against the spindle. Depending on the viscosity of the nanolubricant, changing speeds of the spindle will cause varied shear stress, shear rate, and torque as the temperature rises. The rotational rheometer can measure the viscosity of liquid samples with an accuracy of $0.1 \mathrm{mPas}$ in the range of 1 to $10^{9} \mathrm{mPas}$, as well as accurate temperature control in the range of $0{ }^{\circ} \mathrm{C}$ to $180^{\circ} \mathrm{C}$ with an accuracy of $0.1^{\circ} \mathrm{C}$. The DIN 54453 double gap measuring systems and a viscosity of less than $100 \mathrm{mPa}$.s for low viscosity samples.

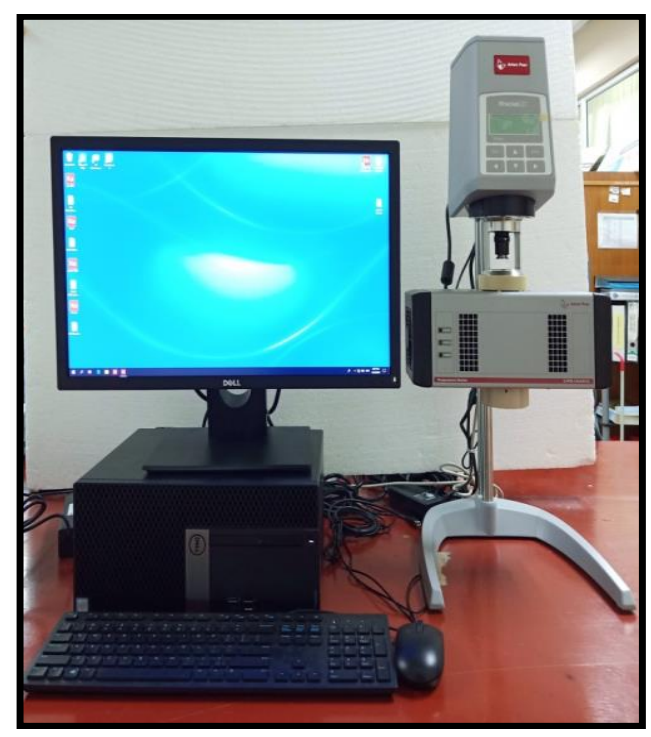

Fig. 4. Anton-Paar Rotational Rheometer Rheolab QC Rheometer

\section{Results and Discussion}

\subsection{Nanolubricant Stability Tests}

Figure 5 presented the absorbance for volume concentrations ranging from 0.01 to $0.1 \%$. The linear relationship between absorbance, $A$, and concentration, $\phi$, was discovered and proved to obey the Beer-Lambert law's linear relationship. The Beer-Lambert law states that the absorbance intensity and nanolubricant concentration have a linear relationship [25, 36].

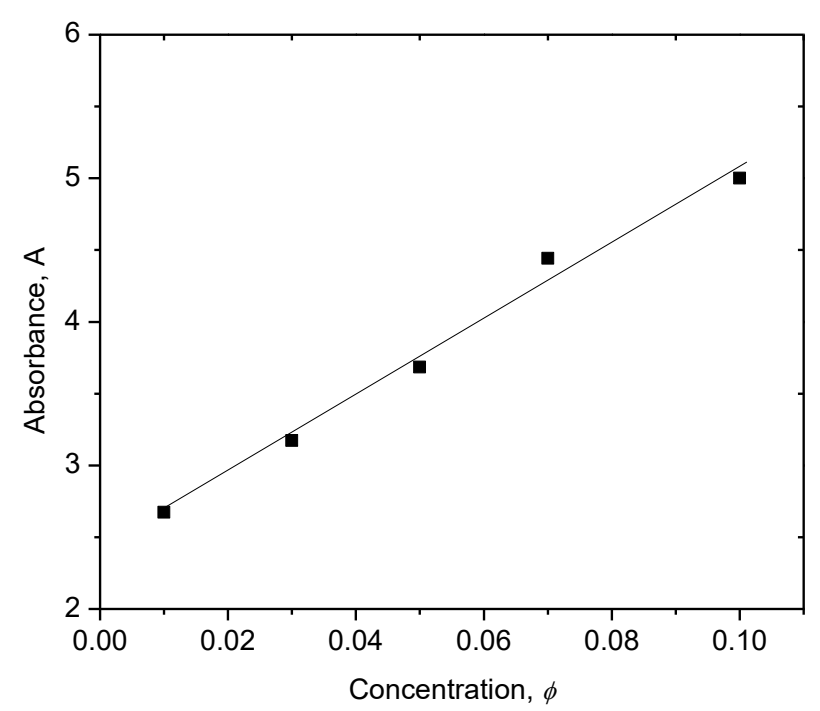

Fig. 5. Linear relation between absorbance and concentration of $\mathrm{TiO}_{2} / \mathrm{POE}$ nanolubricant 
Figure 6 shows the $\mathrm{TiO}_{2} / \mathrm{POE}$ nanolubricant concentration ratio at $0.01 \%$ volume concentration and various sonication hours. The optimal absorbance ratio is one (100\%), indicating that the nanolubricant is stable [39]. From the findings, the concentration ratio started to decrease within 24 hours for all sample for sonication time from 0 to 7 hours. The concentration ratio for reference sample at 0 hour decreased significantly and reached 0.55 ratio on 60 days observation. Meanwhile, concentration ratios for sonication time of $1,3,5$ and 7 hours were remained stable above 0.9 (90\%) on 60 days evaluation. This condition was confirmed the effectiveness of using ultrasonic bath to improve the stability of nanolubricant.

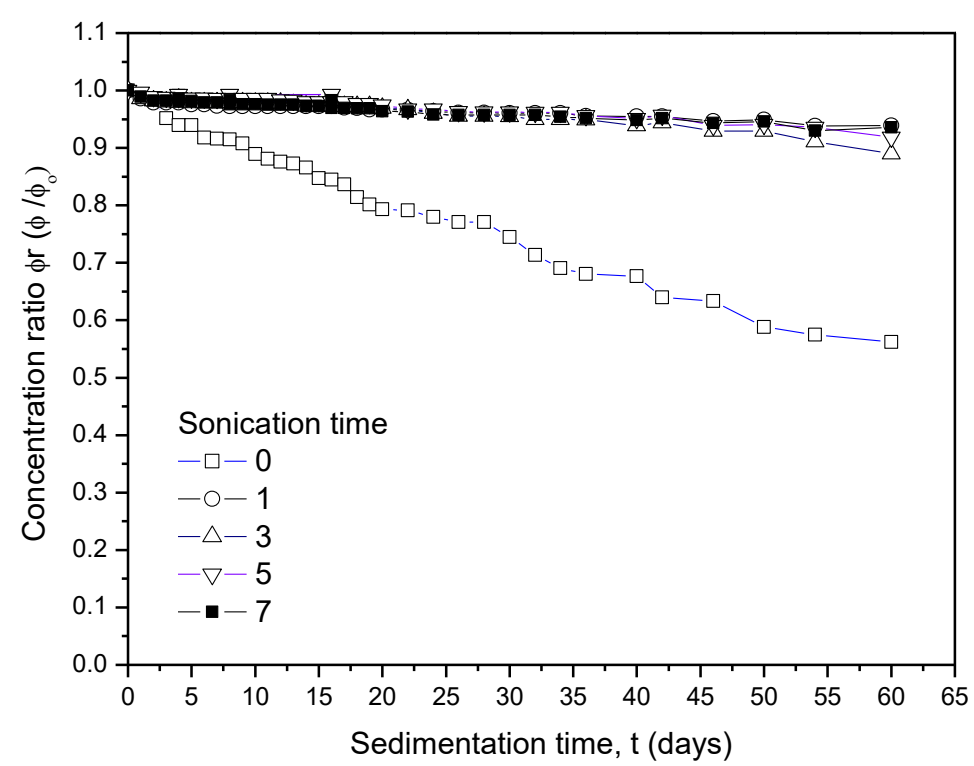

Fig. 6. The concentration ratio of $\mathrm{TiO}_{2} / \mathrm{POE}$ nanolubricant at different sonication time

\subsection{Dynamic Viscosity of Nanolubricant}

\subsubsection{Dynamic viscosity against rotational speed}

Figure 7 depicts the pure POE lubricant viscosity against rotational speed. While Figure 8 depicts the viscosity $\mathrm{TiO}_{2} / \mathrm{POE}$ nanolubricant against rotational speed at $0.01 \%$ volume concentration. It can be seen that the dynamic viscosity of pure $\mathrm{POE}$ lubricant and $\mathrm{TiO}_{2} / \mathrm{POE}$ nanolubricant remains constant with rotational speed at different temperatures. It can be concluded that the pure POE lubricant and $\mathrm{TiO}_{2} / \mathrm{POE}$ nanolubricant behaved as Newtonian fluid at all volume concentration and temperatures. 


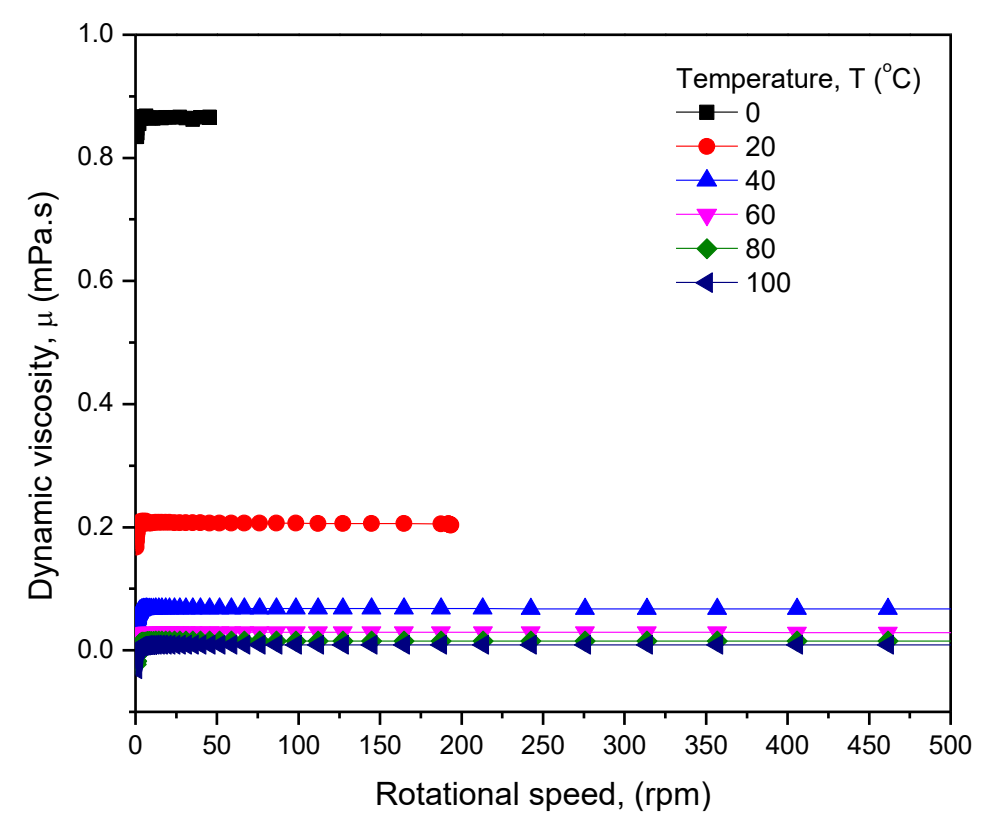

Fig. 7. Pure POE lubricant viscosity against rotational speed

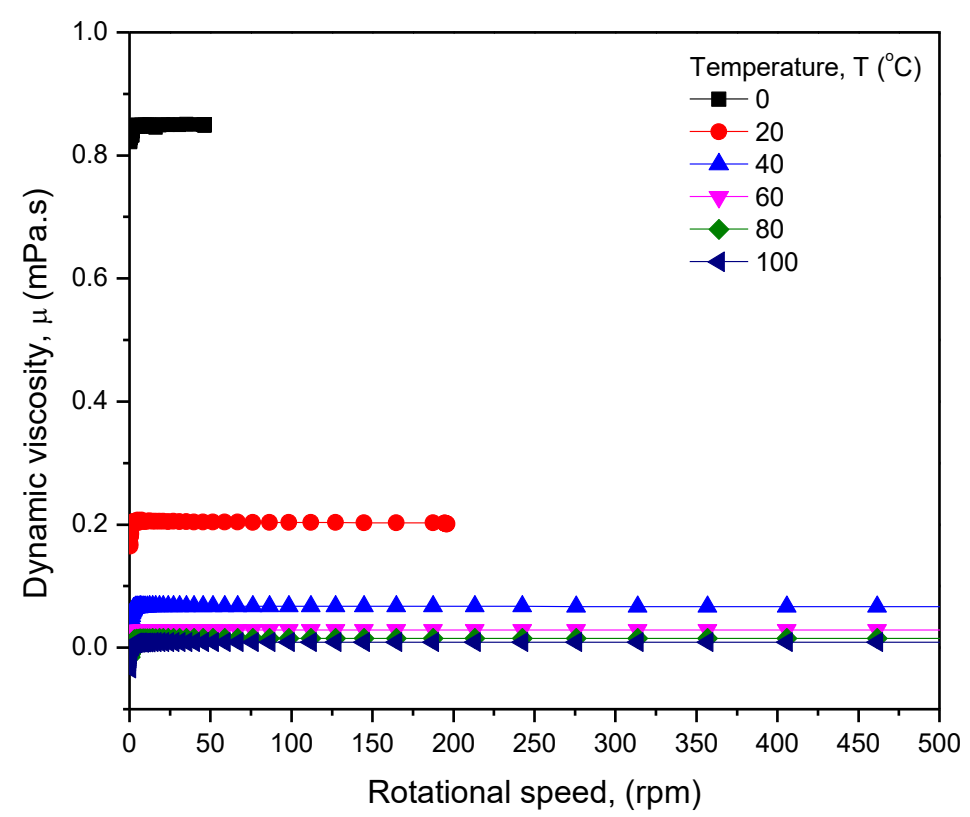

Fig. 8. The viscosity of $\mathrm{TiO}_{2} / \mathrm{POE}$ nanolubricant against rotational speed at $0.01 \%$ volume concentration

\subsubsection{Dynamic viscosity against shear strain rate}

Figure 9 depicts the shear stress against shear strain for pure POE lubricant. While Figure 10 presents the shear stress against shear strain for $\mathrm{TiO}_{2} / \mathrm{POE}$ nanolubricant at $0.01 \%$ volume concentration. It can be observed that the shear stress is directly proportional with the shear strain for different temperatures and applicable for both pure POE lubricant and $\mathrm{TiO}_{2} / \mathrm{POE}$ nanolubricant. It may also be deduced that at all volume concentrations and temperatures, pure POE lubricant and $\mathrm{TiO}_{2} / \mathrm{POE}$ nanolubricant behave as Newtonian fluids. 


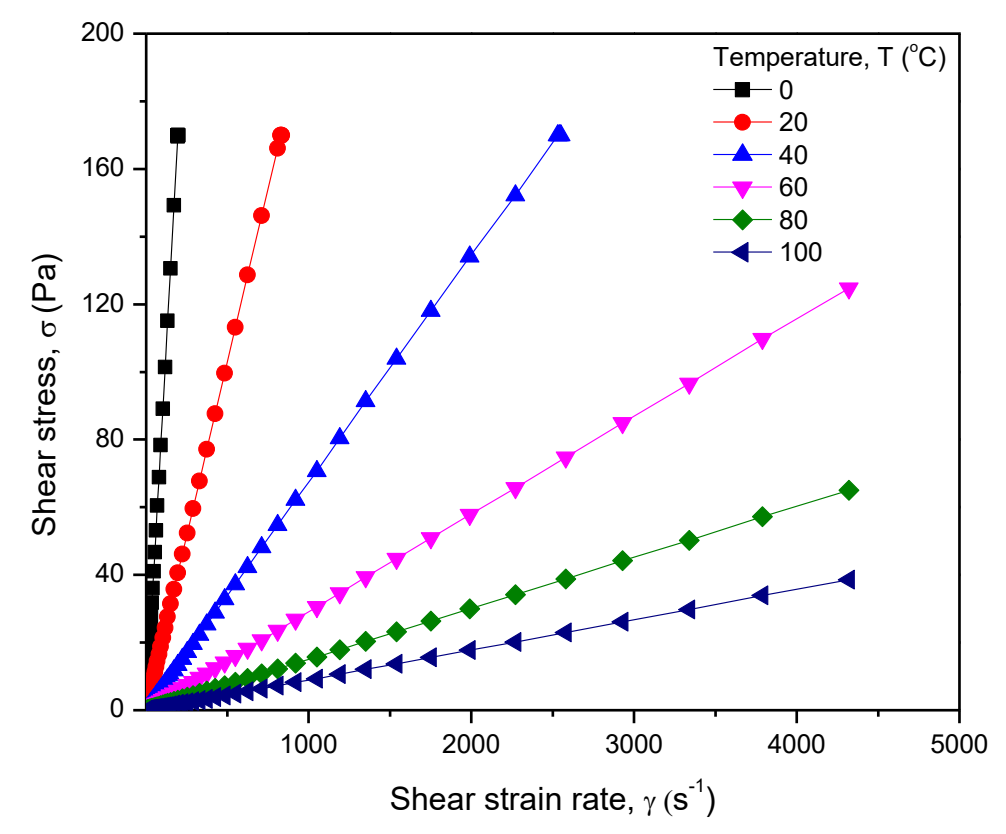

Fig. 9. The pure POE lubricant viscosity against rotational speed

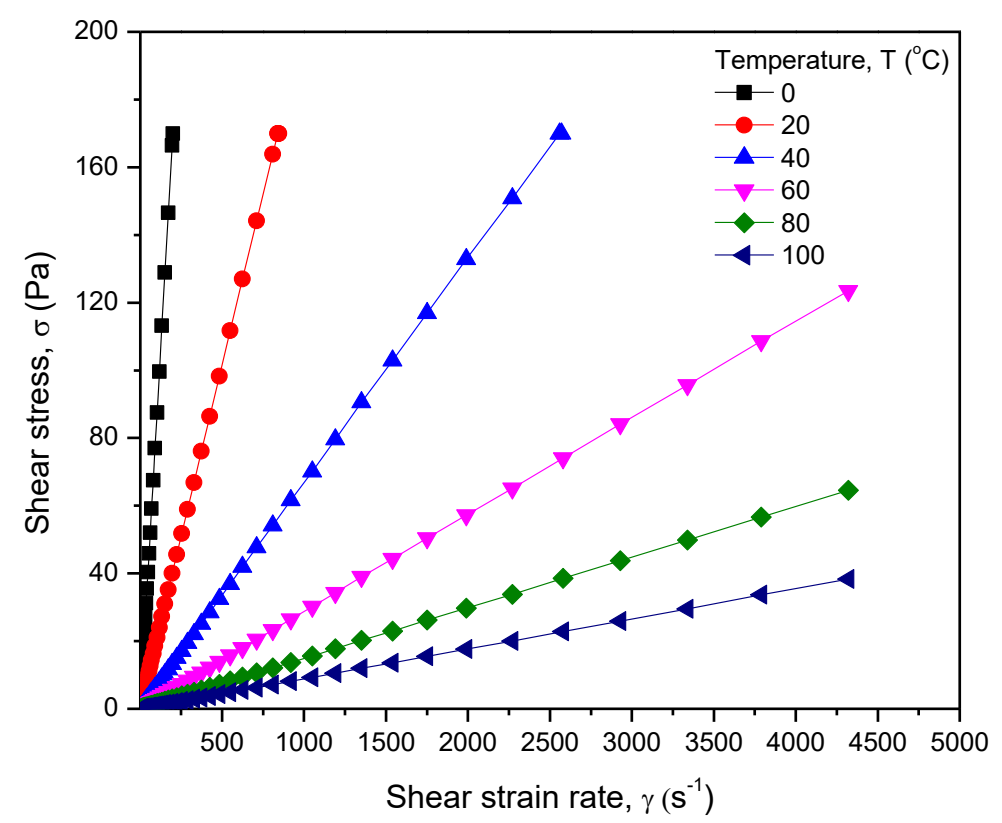

Fig. 10. The 0.01 concentration of $\mathrm{TiO}_{2} / \mathrm{POE}$ nanolubricant shear stress against shear strain rate

\subsubsection{Dynamic viscosity against temperature}

Figure 11 depicts the fluctuation in dynamic viscosity for the $\mathrm{TiO}_{2} / \mathrm{POE}$ nanolubricant at varied temperatures and volume concentrations. The graph shows that the nanolubricant's dynamic viscosity increased significantly with volume concentration. For $0.1 \%$ volume concentration, the increase in dynamic viscosity was only seen at temperatures between 40 and $100^{\circ} \mathrm{C}$. Van der Waals interactions between molecules and liquids are one of the various physical mechanisms that cause the increase in dynamic viscosity [40,41]. In another study, Afrand et al., [42] according to the study, enhancing the connections between nanoparticles and engine oil molecules can increase viscosity. 


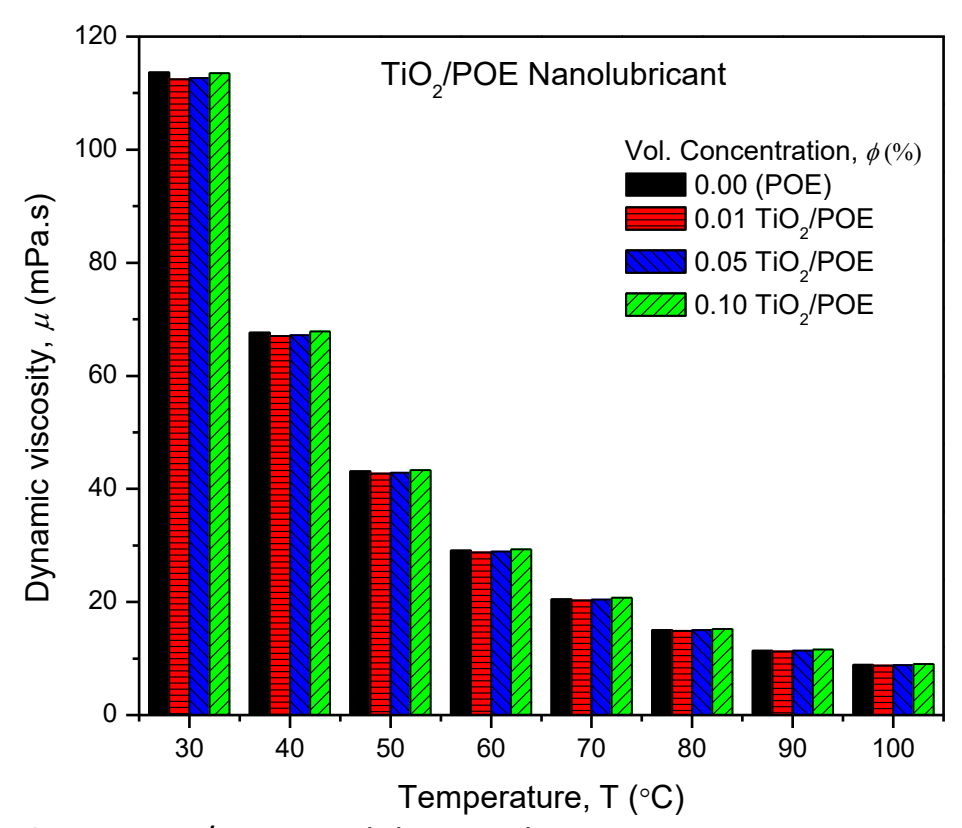

Fig. 11. $\mathrm{TiO}_{2} / \mathrm{POE}$ nanolubricant dynamic viscosity against temperature

Figure 12 depicts the $\mathrm{TiO}_{2} / \mathrm{POE}$ nanolubricant dynamic viscosity increment as a function of temperature. The highest dynamic viscosity increment was observed up to only $1.75 \%$ and occurred at $0.1 \%$ volume concentration and temperatures ranging from 90 to $100^{\circ} \mathrm{C}$. It also agreed well with the data by Zawawi et al., $[7,13,33]$. Interestingly, the dynamic viscosity showed the decrement trend up to $1.8 \%$ for $0.01 \%$ and $0.05 \%$ volume concentration at temperature 0 to $100{ }^{\circ} \mathrm{C}$ compared to pure POE. However, the reduction trend with viscosity of nanolubricants is not common in the literatures. This showed that the nanoparticles did not affect the lubricant in term of the Van der Waals forces but it gives much better and smoother interactions between the nanoparticles and the lubricant compared to pure POE lubricant. The decrement effect of dynamic viscosity means it will decrease the work load of the EDC hence better performance.

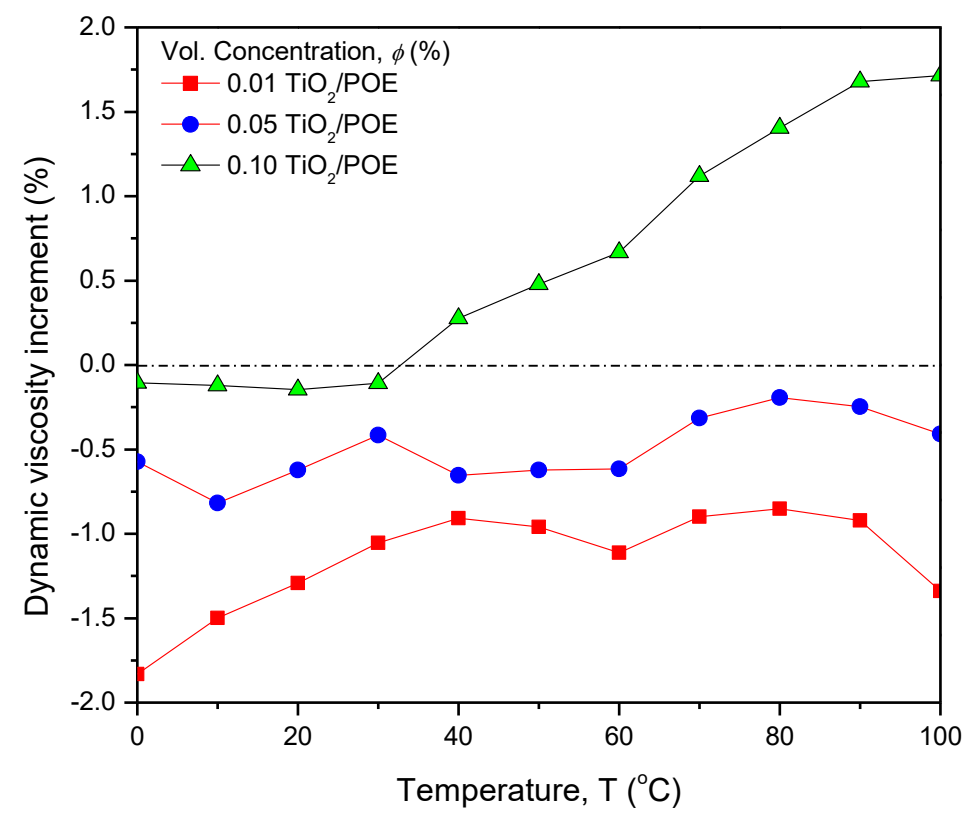

Fig. 12. $\mathrm{TiO}_{2} / \mathrm{POE}$ nanolubricant dynamic viscosity increment against temperature 


\section{Conclusions}

In this paper, $\mathrm{TiO}_{2}$ nanoparticles were dispersed into POE lubricant using a two-step method without the use of any surface stabilizer or surfactant for use in AAC and refrigeration systems. The $\mathrm{TiO}_{2} / \mathrm{POE}$ nanolubricant was observed in excellent stability condition for up to 60 days. The both pure $\mathrm{POE}$ lubricant and $\mathrm{TiO}_{2} / \mathrm{POE}$ nanolubricant behave as Newtonian fluids for all volume concentrations and temperatures. At certain operating temperatures, the $\mathrm{TiO}_{2} / \mathrm{POE}$ nanolubricant demonstrated lower dynamic viscosity than pure POE lubricant for less than $0.1 \%$ volume concentrations. For $0.1 \%$ volume concentration, the increase in dynamic viscosity was only observed at temperatures ranging from 40 to $100^{\circ} \mathrm{C}$. It can be concluded that the $\mathrm{TiO}_{2} / \mathrm{POE}$ nanolubricant outperformed the pure POE lubricant in terms of rheological properties. To extend the current work, additional research on the performance of $\mathrm{AAC}$ systems in $\mathrm{HEVs}$ using the current $\mathrm{TiO}_{2} / \mathrm{POE}$ nanolubricant is required.

\section{Acknowledgement}

The authors would like to thank the Universiti Malaysia Pahang (www.ump.edu.my) for financial supports given under RDU1803169 and Postgraduate Research grant PGRS2003202. The authors also thank the research team from Automotive Engineering Centre (AEC), Centre for Research in Advanced Fluid and Processes and Advanced Automotive Liquids Laboratory (AALL), who provided insight and expertise that greatly assisted in the present research work.

\section{References}

[1] Holmberg, Kenneth, and Ali Erdemir. "Global impact of friction on energy consumption, economy and environment." Fme Trans 43, no. 3 (2015): 181-5.

[2] Choi, S. US, and Jeffrey A. Eastman. Enhancing thermal conductivity of fluids with nanoparticles. No. ANL/MSD/CP84938; CONF-951135-29. Argonne National Lab., IL (United States), 1995.

[3] Kamal, A., A. H. Elsheikh, and E. Showaib. "Pre-Cracking techniques of polymeric materials: an overview." In IOP Conference Series: Materials Science and Engineering, vol. 973, no. 1, p. 012028. IOP Publishing, 2020. https://doi.org/10.1088/1757-899X/788/1/012078

[4] Ramadhan, A. I., W. H. Azmi, and R. Mamat. "Heat transfer characteristics of car radiator using tri-hybrid nanocoolant." In IOP Conference Series: Materials Science and Engineering, vol. 863, no. 1, p. $012054.10 P$ Publishing, 2020. https://doi.org/10.1088/1757-899X/863/1/012054

[5] Azmi, W. H., K. Abdul Hamid, A. I. Ramadhan, and A. I. M. Shaiful. "Thermal hydraulic performance for hybrid composition ratio of $\mathrm{TiO}_{2}-\mathrm{SiO}_{2}$ nanofluids in a tube with wire coil inserts." Case Studies in Thermal Engineering 25 (2021): 100899. https://doi.org/10.1016/i.csite.2021.100899

[6] Ramadhan, A. I., W. H. Azmi, R. Mamat, and K. A. Hamid. "Experimental and numerical study of heat transfer and friction factor of plain tube with hybrid nanofluids." Case Studies in Thermal Engineering 22 (2020): 100782. https://doi.org/10.1016/j.csite.2020.100782

[7] Zawawi, N., W. Azmi, A. Redhwan, and M. Sharif. "Thermo-physical properties of metal oxides composite nano lubricants." J Mech Eng 1 (2018): 28-38.

[8] Hamid, K. Abdul, W. H. Azmi, M. F. Nabil, and Rizalman Mamat. "Experimental investigation of nanoparticle mixture ratios on $\mathrm{TiO}_{2}-\mathrm{SiO}_{2}$ nanofluids heat transfer performance under turbulent flow." International Journal of Heat and Mass Transfer 118 (2018): 617-627. https://doi.org/10.1016/i.ijheatmasstransfer.2017.11.036

[9] Azmi, W. H., N. A. Usri, Rizalman Mamat, K. V. Sharma, and M. M. Noor. "Force convection heat transfer of $\mathrm{Al}_{2} \mathrm{O}_{3}$ nanofluids for different based ratio of water: ethylene glycol mixture." Applied Thermal Engineering 112 (2017): 707-719. https://doi.org/10.1016/i.applthermaleng.2016.10.135

[10] Hamid, K. Abdul, W. H. Azmi, Rizalman Mamat, and K. V. Sharma. "Heat transfer performance of $\mathrm{TiO}_{2}-\mathrm{SiO}_{2}$ nanofluids in a tube with wire coil inserts." Applied Thermal Engineering 152 (2019): 275-286. https://doi.org/10.1016/i.applthermaleng.2019.02.083

[11] Chandrasekar, M., and S. Suresh. "A review on the mechanisms of heat transport in nanofluids." Heat Transfer Engineering 30, no. 14 (2009): 1136-1150. https://doi.org/10.1080/01457630902972744

[12] Lee, S., SU-S. Choi, S, and Li, and J. A. Eastman. "Measuring thermal conductivity of fluids containing oxide nanoparticles." (1999): 280-289. https://doi.org/10.1115/1.2825978 
[13] Zawawi, N. N. M., W. H. Azmi, A. A. M. Redhwan, M. Z. Sharif, and M. Samykano. "Experimental investigation on thermo-physical properties of metal oxide composite nanolubricants." International Journal of Refrigeration 89 (2018): 11-21. https://doi.org/10.1016/j.ijrefrig.2018.01.015

[14] Hamisa, A. H., W. H. Azmi, N. N. M. Zawawi, M. Z. Sharif, and A. I. M. Shaiful. "Comparative Study of Single and Composite Nanolubricants in Automotive Air-Conditioning (AAC) System Performance." In IOP Conference Series: Materials Science and Engineering, vol. 469, no. 1, p. 012044. IOP Publishing, 2019. https://doi.org/10.1088/1757899X/469/1/012044

[15] Ramadhan, Anwar Ilmar, Wan Hamzah AZMI, and Rizalman Mamat. "Experimental investigation of thermo-physical properties of tri-hybrid nanoparticles in water-ethylene glycol mixture." Walailak Journal of Science and Technology (WJST) 18, no. 8 (2021): 9335-15. https://doi.org/10.48048/wjst.2021.9335

[16] Fikri, Mohd Amiruddin, Wan Mohd Faizal, Hasyiya Karimah Adli, Rizalman Mamat, Wan Hamzah Azmi, Zafri Azran Abdul Majid, and Anwar Ilmar Ramadhan. "Characteristic of $\mathrm{TiO}_{2}-\mathrm{SiO}_{2}$ Nanofluid With Water/Ethylene Glycol Mixture for Solar Application." Journal of Advanced Research in Fluid Mechanics and Thermal Sciences 81, no. 2 (2021): 1-13. https://doi.org/10.37934/arfmts.81.2.113

[17] Zhang, Zhenying, Jiayu Wang, Xu Feng, Li Chang, Yanhua Chen, and Xingguo Wang. "The solutions to electric vehicle air conditioning systems: A review." Renewable and Sustainable Energy Reviews 91 (2018): $443-463$. https://doi.org/10.1016/j.rser.2018.04.005

[18] Datta, S. P., and P. K. Das. "Performance of an automotive air conditioning system with the variation of state-ofcharge of the storage battery." International Journal of Refrigeration 75 (2017): $104-116$. https://doi.org/10.1016/i.ijrefrig.2017.01.012

[19] Sharif, M. Z., W. H. Azmi, A. A. M. Redhwan, and R. Mamat. "Investigation of thermal conductivity and viscosity of Al2O3/PAG nanolubricant for application in automotive air conditioning system." international journal of refrigeration 70 (2016): 93-102. https://doi.org/10.1016/i.ijrefrig.2016.06.025

[20] Krishnan, R. Santhana, M. Arulprakasajothi, K. Logesh, N. Dilip Raja, and Mycherla Rajendra. "Analysis and feasibilty of nano-lubricant in vapour compression refrigeration system." Materials Today: Proceedings 5, no. 9 (2018): 20580-20587. https://doi.org/10.1016/i.matpr.2018.06.437

[21] Carlson, Richard Barney, Jeffrey Wishart, and Kevin Stutenberg. "On-road and dynamometer evaluation of vehicle auxiliary loads." SAE International Journal of Fuels and Lubricants 9, no. 1 (2016): $260-268$. https://doi.org/10.4271/2016-01-0901

[22] Fontaras, Georgios, Nikiforos-Georgios Zacharof, and Biagio Ciuffo. "Fuel consumption and CO2 emissions from passenger cars in Europe-Laboratory versus real-world emissions." Progress in energy and combustion Science 60 (2017): 97-131. https://doi.org/10.1016/j.pecs.2016.12.004

[23] Afiq, Aiman Dahlan, A. M. I. R. A. H. Haziqah Zulkifli, Nasution Henry, Abdul Aziz Azhar, MOHD Rozi Mohd Perang, and Hishammudin Mohd Jamil. "Performance Study of Electric Compressor in Non-Electric Vehicle." In Applied Mechanics and Materials, vol. 554, pp. 464-468. Trans Tech Publications Ltd, 2014. https://doi.org/10.4028/www.scientific.net/AMM.554.464

[24] Zulkifli, A. A., A. A. Dahlan, A. H. Zulkifli, H. Nasution, A. A. Aziz, M. R. M. Perang, H. M. Jamil, and M. N. Misseri. "Impact of the electric compressor for automotive air conditioning system on fuel consumption and performance analysis." In IOP Conference Series: Materials Science and Engineering, vol. 100, no. 1, p. 012028. IOP Publishing, 2015. https://doi.org/10.1088/1757-899X/100/1/012028

[25] Sharif, M. Z., W. H. Azmi, A. A. M. Redhwan, R. Mamat, and G. Najafi. "Energy saving in automotive air conditioning system performance using SiO 2/PAG nanolubricants." Journal of Thermal Analysis and Calorimetry 135, no. 2 (2019): 1285-1297. https://doi.org/10.1007/s10973-018-7728-3

[26] Sabareesh, R. Krishna, N. Gobinath, V. Sajith, Sumitesh Das, and C. B. Sobhan. "Application of $\mathrm{TiO}_{2}$ nanoparticles as a lubricant-additive for vapor compression refrigeration systems-An experimental investigation." international journal of refrigeration 35, no. 7 (2012): 1989-1996. https://doi.org/10.1016/i.ijrefrig.2012.07.002

[27] Redhwan, A. A. M., W. H. Azmi, M. Z. Sharif, R. Mamat, and N. N. M. Zawawi. "Comparative study of thermo-physical properties of $\mathrm{SiO} 2$ and Al2O3 nanoparticles dispersed in PAG lubricant." Applied Thermal Engineering 116 (2017): 823-832. https://doi.org/10.1016/i.applthermaleng.2017.01.108

[28] Kedzierski, Mark A., Riccardo Brignoli, K. T. Quine, and J. S. Brown. "Viscosity, density, and thermal conductivity of aluminum oxide and zinc oxide nanolubricants." international journal of refrigeration 74 (2017): 3-11. https://doi.org/10.1016/j.ijrefrig.2016.10.003

[29] Wyczalek, Floyd A. "Heating and cooling battery electric vehicles-the final barrier." IEEE Aerospace and Electronic Systems Magazine 8, no. 11 (1993): 9-14. https://doi.org/10.1109/62.242054

[30] Abdolbaqi, M. Kh, Nor Azwadi Che Sidik, Muhammad Noor Afiq Witri Muhammad Yazid, Rizalman Mamat, W. H. Azmi, and Hind M. Kh. "EXPERIMENTAL AND NUMERICAL INVESTIGATION OF HEAT TRANSFER AUGMENTATION 
USING AL 2 O 3-ETHYLENE GLYCOL NANOFLUIDS UNDER TURBULENT FLOWS IN A FLAT TUBE." Jurnal Teknologi 78, no. 9-2 (2016). https://doi.org/10.11113/jt.v78.9653

[31] Emkarate, RL68H, in: Typical Properties Data Sheet, Lubrizol, CPI Engineering Services, 2016.

[32] Yu, Wei, Huaqing Xie, and Li-Hong Liu. "A review on nanofluids: Preparation, stability mechanisms, and applications." Journal of Nanomaterials 2012, no. 711 (2011): 128. https://doi.org/10.1155/2012/435873

[33] Zawawi, N. N. M., W. H. Azmi, M. Z. Sharif, and G. Najafi. "Experimental investigation on stability and thermophysical properties of Al 20 3-SiO 2/PAG nanolubricants with different nanoparticle ratios." Journal of Thermal Analysis and Calorimetry 135, no. 2 (2019): 1243-1255. https://doi.org/10.1007/s10973-018-7670-4

[34] Sharif, M. Z., W. H. Azmi, A. A. M. Redhwan, N. N. M. Zawawi, and R. Mamat. "Improvement of nanofluid stability using 4-step UV-vis spectral absorbency analysis." Journal of Mechanical Engineering (2017): 233-247.

[35] Usri, N. A., W. H. Azmi, Rizalman Mamat, K. Abdul Hamid, and G. Najafi. "Thermal conductivity enhancement of Al2O3 nanofluid in ethylene glycol and water mixture." Energy Procedia 79 (2015): $397-402$. https://doi.org/10.1016/i.egypro.2015.11.509

[36] Hamisa, A. H., T. M. Yusof, W. H. Azmi, R. Mamat, and M. Z. Sharif. "The stability of TiO $2 / P O E$ nanolubricant for automotive air-conditioning system of hybrid electric vehicles." In IOP Conference Series: Materials Science and Engineering, vol. 863, no. 1, p. 012050. IOP Publishing, 2020. https://doi.org/10.1088/1757-899X/863/1/012050

[37] Sharif, M. Z., W. H. Azmi, A. A. M. Redhwan, and N. M. M. Zawawi. "Preparation and stability of silicone dioxide dispersed in polyalkylene glycol based nanolubricants." In MATEC web of conferences, vol. 90, p. 01049. EDP Sciences, 2017. https://doi.org/10.1051/matecconf/20179001049

[38] Mukherjee, Sayantan, and Somjit Paria. "Preparation and stability of nanofluids-a review." IOSR Journal of Mechanical and civil engineering 9, no. 2 (2013): 63-69. https://doi.org/10.9790/1684-0926369

[39] Ramadhan, A. I., W. H. Azmi, R. Mamat, K. A. Hamid, and S. Norsakinah. "Investigation on stability of tri-hybrid nanofluids in water-ethylene glycol mixture." In IOP Conference Series: Materials Science and Engineering, vol. 469, no. 1, p. 012068. IOP Publishing, 2019. https://doi.org/10.1088/1757-899X/469/1/012068

[40] Rudyak, Valery Ya. "Viscosity of nanofluids. Why it is not described by the classical theories." Advances in nanoparticles 2, no. 03 (2013): 266. https://doi.org/10.4236/anp.2013.23037

[41] Nabil, M. F., W. H. Azmi, K. A. Hamid, N. N. M. Zawawi, G. Priyandoko, and R. Mamat. "Thermo-physical properties of hybrid nanofluids and hybrid nanolubricants: a comprehensive review on performance." International Communications in Heat and Mass Transfer 83 (2017): https://doi.org/10.1016/i.icheatmasstransfer.2017.03.008

[42] Afrand, Masoud, Karim Nazari Najafabadi, and Mohammad Akbari. "Effects of temperature and solid volume fraction on viscosity of SiO2-MWCNTs/SAE40 hybrid nanofluid as a coolant and lubricant in heat engines." Applied Thermal Engineering 102 (2016): 45-54. https://doi.org/10.1016/i.applthermaleng.2016.04.002 